\title{
Postoperative Renal Injury in Heart Surgery
}

Aslı Demir (1)

Etik Kurul Onayı: Hastane Yerel Etik Kurul onayı alınmıştır (Tarih 11.5.18, No: 5808) Çıkar Çatışması: Bu makalenin yazarı ve/veya yayınlanması ile ilgili çıkar çatışmas yoktur.

Finansal Destek: Yazarlar bu makalenin araştırma ve/veya yazarlığı için herhangi bir maddi destek almamışlardır.

Hasta Onamı: Retrospektif bir çalışma olduğu için hasta onamı alınmamıştır.
Ethics Committee Approval: Hospital local ethics committee approved (date: 11.5.18, no: 5808)

Conflict of Interest: No conflicts of interest with respect to the authorship and/or publication of this article.

Funding: The authors received no financial support for the research and/or authorship of this article. Informed Consent: No patient consent was obtained because it was a retrospective study.

Cite as: Altınkaya Çavuş M, Gökbulut Bektaş ş, Demir A. Kalp cerrahisinde postoperatif renal hasar, GKDA Derg. 2019;25(2):126-32.

öz

Amaç: Kardiyak cerrahi, sonrasında birçok önemli komplikasyonun olduğu karmaşık patofizyolojik durumlar içerir. En önemli komplikasyon olan böbrek yetmezliği artmış morbidite ve mortalitaden sorumludur.

Yöntem: 2016-2018 yılları arasında hastanemizde yapılan 2600 açık kalp ameliyatı geçiren hastaların dosyaları retrospektif olarak tarandı.

Bulgular: 2.600 açık kalp ameliyatı geçiren hastaların 105'inde, postoperatif renal yetmezlik gelişmiştir.

Sonuç: Renal yetmezlik; erkek cinsiyet, diyabet ve periferik damar hastalığı, önceden geçirilmiş miyokard enfarktüsü, kötü ejeksiyon fraksiyonu (<\%50), anemi, kontrast madde maruziyeti, nonsteroid antiiflamatuar (NSAi) ve antihipertansif ilaçlar, uzamış kardiyopulmoner baypas (KPB) süresi ile ilişkilidir.

Anahtar kelimeler: postoperatif böbrek yetmezliği, kardiyak anestezi, postoperatif morbidite, postoperatif mortalite, renal hasarlanma, postoperatif diyaliz

\section{ABSTRACT}

Objective: Cardiac surgery involves complex pathophysiologic conditions, which are followed by many important complications. Renal failure is the most important complication, responsible for increased morbidity and mortality.

Method: The files of the patients who underwent 2600 open heart surgeries in our hospital between 2016-2018 were retrospectively reviewed.

Results: Postoperative renal failure developed in 105 of 2600 patients who had undergone open heart surgery.

Conclusion: Renal failure is associated with male sex, diabetes and peripheral vascular disease, previous myocardial infarction, poor ejection fraction $(<50 \%)$, anemia, exposure to contrast agent, use of nonsteroidal anti-inflammatory drugs (NSAIDs) and(or antihypertensive drugs, and prolonged cardiopulmonary bypass surgery (CPB).

Keywords: Postoperative renal failure, cardiac anesthesia, postoperative morbidity, postoperative mortality, renal injury, postoperative dialysis
Alındığı tarih: 07.10.2018

Kabul tarihi: 27.11.2018

Yayın tarihi: 30.06.2019

Mine Altınkaya Çavuş Türkiye Yüksek İhtisas EAH Kızılay Sok. Sıhhiye Ankara-Turkey minealtinkaya@yahoo.com ORCID: 0000-0003-2584-0463

Ş. G. Bektaş 0000-0001-6057-723X A. Demir 0000-0003-3053-0443

Türkiye Yüksek Ihtisas EAH Kızılay Sok. Sıhhiye Ankara-Turkey

\section{GíRiş}

Açık kalp cerrahisi sonrası diyaliz gerektiren renal hasarlanma, mortalite ve morbiditeyi arttıran, sağlık bakım maliyetlerini yükselten ciddi komplikasyonların gelişimi açısından iyi bilinen bir risk faktörüdür [1-3]. Kalp cerrahisinde postoperatif akut renal hasar, hastaların \%3-30'unda görülürken, \%1-5 hastada diyaliz tedavisi gerektiren hasarlanma gelişir ${ }^{[4,5]}$. Postoperatif dönemde diyaliz gerektiren böbrek yetmezliği gelişen hastalarda mortalite \%37-60 iken, gelişmeyen hastalarda bu oran \%2-8 olarak bildirilmiştir ${ }^{(6,7)}$. Serum kreatininindeki küçük değişiklikler bile morbidite ve mortalitede artış ile ilişkili bulunurken

C Telif hakkı Göğüs Kalp Damar Anestezi ve Yoğun Bakım Derneği'ne aittir. Logos Tıp Yayıncılık tarafindan yayınlanmaktadır Bu dergide yayınlanan bütün makaleler Creative Commons Attf-Gayri Ticari 4.0 Uluslararası Lisansı ile lisanslanmıştr. 
diyaliz gerektiren renal hasarlanma çok daha major bir postoperatif komplikasyon olarak karşımıza çıkmaktadır ${ }^{[8]}$. Postoperatif akut renal hasarlanmanın etiyolojisi multifaktöriyel olmakla beraber, inflamatuar yanıt ve perioperatif hipovolemi sıklıkla sorumlu tutulmaktadır ${ }^{[9]}$. Günümüzde cerrahi sırasında böbrek fonksiyonlarının korunmasının proflaktik stratejileri arasında nefrotoksik ajanlardan kaçınılması ve böbrek hipoperfüzyonunun önlenmesi yer almaktadır. Bugüne kadar perioperatif renal hasarı önleyebilecek bir farmakolojik ajan henüz tanımlanmamıştır. Renal hasar açısından riskli hastaların tanınması, gelişebilecek böbrek yetmezliğini geri dönüşlü bir aşamada yakalayıp daha agresif bir tedavi uygulanmasına izin verebilir.

Bu makalede, son iki yıl içinde açık kalp cerrahisi geçirmiş hastalarda, ameliyat sonrasında, yeni gelişmiş, diyaliz gerektiren böbrek yetmezliği olan olguların özelliklerini incelemeyi amaçladık.

\section{GEREÇ ve YÖNTEM}

Hastanemiz Retrospektif Çalışmalar Etik Kurulundan 41 sayı ve 29.05.2018 tarih numarası ile onay alındıktan sonra, merkezimizde son 2 yıl içinde kardiyopulmoner baypas kullanılarak ameliyat edilmiş 2600 hasta olduğu belirlendi. Bunların arasından preoperatif renal sorunu olmadığı hâlde postoperatif dönemde diyaliz gerektiren böbrek yetmezliği gelişen 105 hastanın verilerine ulaşıldı. Pediyatrik hastalar, off-pump cerrahiler, vasküler cerrahi geçiren hastalar ile önceden kronik böbrek yetmezliği/diyaliz öyküsü olan hastalar retrospektif gözlemsel çalışmamıza dâhil edilmedi. Hastane elektronik veri tabanından ve arşivden dosya taraması yapılarak bu hastaların perioperatif verilerine ulaşıldı. Kliniğimizde rutin uygulanan alfa stat kan gazı, orta dereceli hipotermi $\left(28-32{ }^{\circ} \mathrm{C}\right)$, nonpulsatil pompa akımı, dengeli anestezi yönetimi (Bilinç kaybı ve reflekslerin baskılanması ile birlikte nöromüsküler kavşağın bloke edilmesinin birlikte uygulandığı anestezi şeklidir.) ve kısmi hasta kan yönetimi uygulamaları (Gereksiz transfüzyonları önlemek yanında hastanın transfüzyon alma olasılığı- nı en aza indirmeye ve kendi kan rezervini optimize etmeye yönelik tüm uygulamaları içerir.) bütün olgularda standarttı. Yüksek opioidli dengeli anestezi; 10 $\mu \mathrm{g} / \mathrm{kg}$ fentanil, $0.1 \mathrm{mg} / \mathrm{kg}$ midozolam, $0.6 \mathrm{mg} / \mathrm{kg}$ roküronyum ile sağlandı. Demografik bilgilerin yanında preoperatif komorbiditeleri, medikasyonları, kontrast madde maruziyetleri, hemoglobin, glukoz, lökosit ve kreatinin değerleri kaydedildi. İntraoperatif döneme ait cerrahi tipi, kardiyopulmoner baypas (KPB) süresi, kan ve kan ürünü transfüzyonları, medikasyonları, ultrafiltrasyon, ekstrakorporyal membran oksijenasyonu (ECMO) ve intraaortik balon pompası (IABP) kullanımları, kan gazları, en düşük hemoglobin, delta hemoglobin, en yüksek glukoz ve en düşük Isı değerleri kaydedildi. Postoperatif dönemde renal hasarlanmanın yanı sıra geliş̧ı̧̧ diğer komplikasyonlar, diyaliz sayısı, mortalite bilgileri de değerlendirildi.

\section{İstatistiksel Analiz}

Normal olarak dağıtılan sürekli değişkenler, normal dağılmadığı takdirde, ortalama değerıstandart sapma (sd) veya ortanca değer ile en düşük ve en yüksek değer olarak ifade edildi. Kategorik değişkenler sayı ve yüzde olarak ifade edildi. Tüm istatistiksel analizler spss istatistik yazılımı (spss for windows 15.0, inc., Chicago, il, ABD) kullanılarak yapıldı.

\section{BULGULAR}

Hastanemizde son 2 yıl içerisinde kardiyopulmoner baypas eşliğinde açık kalp cerrahisi geçiren 2.600 hasta arasından, yeni gelişmiş diyaliz gerektiren böbrek yetmezliği olan 105 hasta olduğu saptandı (\%4). Hastaların ortalama yaşı $57.6 \pm 15,5$ iken, erkek cinsiyet tüm hastaların \%67'sini oluşturmaktaydı. Hastaların \%35.2'sine hipertansiyon, \%30,5'ine diyabet eşlik etmekteydi. Son 1 ay içinde anjiografi veya başka bir nedenle kontrast maddeye maruz kalma \%73.3 oranında bulundu. Acil cerrahi geçiren hastalar \%29.7 oranındaydı (Tablo 1). İntraoperatif özellikler Tablo 2'de verildi, buna göre hastalara en sık uygulanan ameliyat çeşidi \%35.2 ile koroner baypas cerrahisi oldu. Bunu kapak cerrahisi (\%19), aort diseksiyonu (\%17.1), çoklu cerrahi prosedürler (\%12) 
Tablo 1. Preoperatif demografik veriler.

\begin{tabular}{|c|c|c|}
\hline Özellikler & ortalama $\pm S D$ veya $n(\%)$ & Medyan (IQR) \\
\hline Yaş (yıl) & $57.6 \pm 15.5$ & $61(49-68)$ \\
\hline Erkek cinsiyet & $67(\% 63.8)$ & \\
\hline Hipertansiyon & $37(\% 35.2)$ & \\
\hline Diyabet & $32(\% 30,5)$ & \\
\hline Prostat hastalığı & $0(\% 0)$ & \\
\hline Periferik arter hastalığı & 2 (\%1.9) & \\
\hline KOAH* & $8(\% 7.6)$ & \\
\hline Karotis arter hastalığı & 1 (\%1.0) & \\
\hline Hiperlipidemi & $6(\% 5.7)$ & \\
\hline Marfan sendromu & $1(\% 1.0)$ & \\
\hline Beden kitle indeksi (BKi) & $27.1 \pm 4.7$ & $26.4(24.1-28.4)$ \\
\hline EF (\%) & $41.9 \pm 16.6$ & $45(28-56)$ \\
\hline Son 1 aydaki kontrast maruziyeti & 77 (\%73.3) & \\
\hline Son 3 hafta içindeki MI** & $9(\% 8.6)$ & \\
\hline \multicolumn{3}{|l|}{ Tedaviler } \\
\hline Beta-blokörler & 35 (\%33.3) & \\
\hline ACE inhibitörü & $10(\% 9,5)$ & \\
\hline Ca kanal blokörü & 15 (\%14.3) & \\
\hline Oral anidiyabetikler & $11(\% 10,5)$ & \\
\hline Diüretikler & $21(\% 20.0)$ & \\
\hline NSAID & $20(\% 19.0)$ & \\
\hline Bronkodilatatörler & $1(\% 1.0)$ & \\
\hline \multicolumn{3}{|l|}{ Preoperatif laboratuar değerleri } \\
\hline Hemoglobin & $12.4 \pm 2.1$ & $12.6(11.4-13.7)$ \\
\hline Glukoz & $147.8 \pm 77.4$ & $120(95-175)$ \\
\hline Beyaz küre & $10.1 \pm 4.6$ & $8.6(7.3-11.5)$ \\
\hline Üre & $55.5 \pm 295$ & $43(35-72)$ \\
\hline Kreatin & $1.26 \pm 0.78$ & $1.09(0,86-1.45)$ \\
\hline
\end{tabular}

*Kronik obstrüktif akciğer hastalığı, **Miyokard infarktüsü.

\section{Tablo 2. Operatif-postoperatif özellikler.}

\begin{tabular}{|c|c|c|}
\hline Özellikler & ortalama $\pm S D$ veya $n(\%)$ & Medyan (IQR) \\
\hline $\begin{array}{l}\text { Ameliyat çeşidi } \\
\text { Koroner baypas } \\
\text { Kapak } \\
\quad \text { Aort diseksiyonu } \\
\text { Sol ventrikül mekanik destek } \\
\text { Kalp nakli } \\
\text { Kombine cerrahiler } \\
\text { Acil cerrahi } \\
\text { Kros-klamp zamanı (dk.) } \\
\text { KPB zamanı (dk.) } \\
\text { Ameliyat zamanı (dk.) } \\
\text { Eritrosit transfüzyonu (ünite) } \\
\text { Taze donmuş plazma transfüzyonu (ünite) }\end{array}$ & $\begin{array}{c}37(\% 35.2) \\
20(\% 19.0) \\
18(\% 17.1) \\
9(\% 8.6) \\
9(\% 8.6) \\
12(\% 11,5) \\
31(\% 29.7) \\
94.4 \pm 56.6 \\
152.5 \pm 80.5 \\
254.7 \pm 98.3 \\
1.45 \pm 1.37 \\
0.47 \pm 0.72\end{array}$ & $\begin{array}{c}82.5(57-122) \\
133(94-196) \\
240(180-300) \\
1(0-3) \\
0(0-1)\end{array}$ \\
\hline $\begin{array}{l}\text { Tedaviler } \\
\text { Insülin } \\
\quad \text { Furosemide } \\
\quad \text { Mannitol (92 hasta - \%87.6) } \\
\quad \text { Transamik asit } \\
\text { Steroid (37 hasta - \%35.2) } \\
\text { Ultrafiltrasyon (31 hasta - \%29,5) } \\
\text { Idrar çıkışı (mL) } \\
\text { IABP } \\
\text { ECMO } \\
\text { IABP+ECMO } \\
\text { En düşük hemoglobin } \\
\text { Delta haemoglobin } \\
\text { En düšük sıcaklık } \\
\text { En yüksek glikoz }\end{array}$ & $\begin{array}{c}22(\% 21.0) \\
27(\% 25.7) \\
174.9 \pm 42.1 \\
8(\% 7.8) \\
270.0 \pm 112.6 \\
1195 \pm 412 \\
862 \pm 585 \\
20(\% 19.0) \\
5(\% 4.8) \\
7(\% 6.7) \\
7.07 \pm 1.33 \\
4.14 \pm 2.03 \\
30.9 \pm 3.0 \\
206.1 \pm 53.9\end{array}$ & $\begin{array}{c}150(150-200) \\
250(250-250) \\
1100(1000-1500) \\
800(450-1200)\end{array}$ \\
\hline $\begin{array}{l}\text { Postoperatif değerler } \\
\text { Hemoglobin } \\
\text { Glukoz }\end{array}$ & $\begin{array}{c}8.68 \pm 1.28 \\
183.2 \pm 62.3\end{array}$ & $\begin{array}{c}8,8(8.0-9.4) \\
181(143-215)\end{array}$ \\
\hline
\end{tabular}




\section{Tablo 3. Kan gazı değerleri.}

\begin{tabular}{|c|c|}
\hline AKG (arter kan gazı) & Ortalama \pm SD \\
\hline \multicolumn{2}{|l|}{ AKG $1 *$} \\
\hline $\mathrm{pH}$ & $7.38 \pm 0.10$ \\
\hline $\mathrm{pCO}_{2}$ & $35.0 \pm 5,5$ \\
\hline $\mathrm{pO}_{2}^{2}$ & $144.4 \pm 61.3$ \\
\hline $\mathrm{Hb}^{2}$ & $11.0 \pm 2.2$ \\
\hline $\mathrm{BE}$ & $-4.0 \pm 3.1$ \\
\hline \multicolumn{2}{|l|}{ AKG $2 * *$} \\
\hline $\mathrm{pH}$ & $7.35 \pm 0.13$ \\
\hline $\mathrm{pCO}_{2}$ & $34.0 \pm 5.4$ \\
\hline $\mathrm{pO}_{2}{ }^{2}$ & $184,5 \pm 62.1$ \\
\hline $\mathrm{Hb}^{2}$ & $8.2 \pm 2.8$ \\
\hline $\mathrm{BE}$ & $-4.2 \pm 3.9$ \\
\hline \multicolumn{2}{|l|}{ AKG $3 * * *$} \\
\hline $\mathrm{pH}$ & $7.32 \pm 0.12$ \\
\hline $\mathrm{pCO}_{2}$ & $38.2 \pm 5.1$ \\
\hline $\mathrm{pO}_{2}^{2}$ & $130.9 \pm 51.1$ \\
\hline $\mathrm{Hb}^{2}$ & $8.5 \pm 1.4$ \\
\hline $\mathrm{BE}$ & $-5.3 \pm 3.3$ \\
\hline \multicolumn{2}{|l|}{ AKG $4 * * *$} \\
\hline $\mathrm{pH}$ & $7.35 \pm 0.13$ \\
\hline $\mathrm{pCO}_{2}$ & $33.0 \pm 5.6$ \\
\hline $\mathrm{pO}_{2}{ }^{2}$ & $121.3 \pm 45.2$ \\
\hline $\mathrm{Hb}^{2}$ & $9.0 \pm 1.3$ \\
\hline $\mathrm{BE}$ & $-5.0 \pm 3.7$ \\
\hline
\end{tabular}

*KPB öncesi kan gazı değerleri, **KPB sırasında kan gazı değerleri, ***KPB sonrasında kan gazı değerleri.

****Postoperatif 1. gün kan gazı değerleri.

ve yetmezlik cerrahisi [LVAD (sol ventrikül destek cihazı) \%9 ve transplantasyon \%9] olguları izledi. Ortalama KPB süresi 152.5£80,5 dk idi, KPB sırasında en düşük hemoglobin ve en düşük sıcaklık değerleri ile en yüksek glukoz değerleri Tablo 2'de verildi. Ameliyat sırasında \%29,5 hastaya ultrafiltrasyon, \%30,5 hastaya IABP ve/veya ECMO uygulandığı görüldü (Tablo 2). Perioperatif kan gazı bilgileri Tablo 3'te ve postoperatif komplikasyonlar ile renal hasarlanma bilgileri ise Tablo 4'te görülmektedir. Buna göre, kalı$\mathrm{Cl}$ renal hasar $\% 72.4$ gözlenirken, 28 günlük mortalite 50 hastada (\%47.6), 3 aylık mortalite 64 hastada (\%71) mevcuttu.

\section{TARTIŞMA}

Hastanemizde son 2 yılda açık kalp cerrahisi yapıldıktan sonra yeni gelişmiş, diyaliz gerektiren renal hasarlanma oranı \%4 bulundu. Kardiyak cerrahi sonrası akut renal hasar oranı cerrahi tipine ve bazal

\section{Tablo 4.}

\begin{tabular}{|c|c|}
\hline Özellikler & $\begin{array}{c}\text { Ortalama } \pm \text { SD } \\
\text { veya } n(\%)\end{array}$ \\
\hline
\end{tabular}

Diğer komplikasyonlar Komplikasyon yok

Nörolojik

$41(\% 39)$

Kanama nedenli revizyon

$30(\% 28.6)$

$9(\% 8.6)$

Sepsis

$5(\% 4.8)$

$5(\% 4.8)$

$3(\% 2.9)$

$3(\% 2.9)$

$3(\% 2.9)$

$3(\% 2.9)$

$3(\% 2.9)$

$5,5 \pm 5.8$

$4(2-6)$

Gis komplikasyon

Diyaliz sayısı

Renal morbidite

Geçici dializ gereksinim $\quad 29(\% 27.6)$

Kalıcı dializ gereksinim $76(\% 72.4)$

Mortalite (3 ay)

$64(\% 71.0)$

Mortalite (28 gün)

değişkenlere bağlı olmakla birlikte, \%8.9-39 gibi geniş bir aralıkta gözlenmektedir ${ }^{[10]}$. Bunların arasında renal replasman tedavisi gerektirecek kadar ciddi hasarlanma ise \%1-5 olguda ortaya çıkmaktadır ${ }^{(4,5,11)}$. İleri yaş (70 y), kadın cinsiyet, diyabet ve periferik damar hastalığı, önceden geçirilmiş miyokard enfarktüsü, kötü sol ventrikül ejeksiyon fraksiyonu (EF) (<\%50) renal hasarlanma açısından risk olarak değerlendirilmektedir ${ }^{(8,12)}$. Hasta grubumuzda yaş ortalaması (57 y) yaşlı kabul edilen düzeyde değildi ve erkek cinsiyet ağırlıklı bulundu (\%63.8). Renal hasar gelişmiş hastalarımızda diyabet $\% 30,5$ hastada, periferik damar hastalığı \%1.9 hastada, geçirilmiş enfarktüs \%8.6 hastada gözlendi. Genel olarak preoperatif sol ventrikül EF ortalaması \%50'nin altında idi.

Nefrotoksik olan bazı ilaçların preoperatif dönemde kullanılması postoperatif renal hasarlanma için risk kabul edilen bir diğer konudur. Bu açıdan direkt toksik etkisi olan nonsteroid antiiflamatuar (NSAi) ve anjiyotensin dönüştürücü enzim (ACE) inhibitörü gibi ilaçların yanında, ortalama arter basıncını düşürerek renal perfüzyonu bozduğu düşünülen diğer antihipertansif ajanlar da suçlanmaktadır ${ }^{[13]}$. Çalışma grubumuzda preoperatif dönemde NSAID ve ACE inhibi- 
törleri de dâhil antihipertansif ilaç kullanan hastalar \%96 oranında bulundu. Bu oldukça yüksek oran kardiyak cerrahiye hazırlanan hastalar için pek şaşırtıcı değildir. Bu medikasyonların yanı sıra kontrast madde maruziyeti oldukça önemli bir etiyolojik faktördür. Özellikle yakın zamanda anjiografi veya diğer nedenlerle kontrast madde alımının postoperatif dönemde renal hasarlanma için zemin yarattığı bilinmektedir (8). Bu açıdan hasta grubumuzda, tıpkı yüksek antihipertansif ilaç kullanımı gibi yine yüksek oranda (\%73.3) son 1 ay içinde kontrast maruziyeti saptanmıştır.

Thakar ${ }^{(14)}$ tarafından postoperatif akut böbrek yetmezliğini klinik olarak tahmin etme skorlaması yapılmıştır. Buna göre acil cerrahi girişimler, kombine kardiyak girişimler ve baypas ve kapak harici diğer kardiyak girişimler 2 puan alarak daha yüksek risk göstergesi kabul edilmektedir. Hasta grubumuzda \%29.7 hastaya acil cerrahi uygulanırken, \%45.8 hastaya da baypas ve kapak harici kardiyak cerrahiler yapılmıştır. Bu oranların rutin kardiyak cerrahi uygulamalarına göre oldukça yüksek olduğu gözlenmektedir. Preoperatif kreatinin yüksekliği Thakar sınıflamasında riskli kabul edilen bir diğer parametredir, ancak biz, çalışma planımızda preoperatif hiçbir hastada renal patoloji bulunmamasını tercih ettik (kreatinin $1.26 \mathrm{~g} / \mathrm{dL}$ ). Bu sayede yeni gelişmiş ve diyaliz gerektirecek kadar ileri renal hasarlanmanın hangi hastalarda ortaya çıktığını gözlemek istedik.

Preoperatif anemi postoperatif renal yetmezlik için risk olarak değerlendirilen önemli bir durumdur ${ }^{(15)}$. Hemoglobin değeri $13 \mathrm{~g} / \mathrm{dL}$ 'nin altında olan hastalarda ameliyat sonrası renal yetmezlik $\% 18,5$ iken anemik olmayanlarda bu oran $\% 6,5$ olarak bulunmuştur (15). Bağlantılı olarak aneminin hastanede kalımı ve mortaliteyi arttırdığı da bilinmektedir $(15,16)$. Hastalarımızda ortalama hemoglobin değeri $12.4 \mathrm{~g} /$ $\mathrm{dL}$ idi, birçok hastada orta dereceli anemi varlığı saptandı. Transfüzyonun da anemi gibi mortalite ve morbiditeyi arttırdığı bilinmektedir ${ }^{[17]}$, ancak hastalarımızda transfüzyon oranları oldukça kabul edilebilir düzylerde saptandı. İnflamatuar nedenlerle indük- lenen olumsuz süreçler uzun kardiyopulmoner baypas süresinin, postoperatif renal hasarlanmaya katkıda bulunduğunu göstermektedir ${ }^{[18]}$. Her ne kadar güvenli kardiyopulmoner baypas (KPB) süresi hakkında net bir görüş olmasa da 120 dk.'dan fazla süren KPB'ın riskli olabileceği genel kanıdır. Hasta grubumuzda ortalama KPB süresi 152.5 dk. ile oldukça uzun bulundu. Ayrıca intraoperatif dönemde IABP \%19, ECMO \%4.8 hastaya ve her ikisi birden \%6.7 hastada kullanılmıştı. Risk faktörü olarak kabul edilen bu kullanımların da hastalarımızda yüksek olduğu göze çarpmaktadır ${ }^{[14]}$.

Hasta grubumuzda KBP sırasındaki en düşük hemoglobin düzeyi $7 \mathrm{~g} / \mathrm{dl}$ bulundu. Renal oksijenasyon için kritik değerin $8 \mathrm{~g} / \mathrm{dl}$ olduğunu öne süren çalışmalara göre intraoperatif anemi de renal hasar için riskli bir klinik durumdur ${ }^{[19,20]}$. Bu derecede hemodilüsyon ve anemi de renal hasara katkıda bulunan faktörlerden biri olarak karşımıza çıkmaktadır.

Kalp cerrahisinde sıklıkla kullanılan hipotermi ve sonrasında yeniden ısınmanın renal hasarlanmaya katkısı ile ilgili çelişkili sonuçlar mevcuttur ${ }^{[17]}$, hastalarımızda derin hipotermi kullanılmamıştır. Yine KPB sırasındaki embolik faktörlerin de hasara katkısından söz edilmektedir, ancak bunu değerlendirecek herhangi bir tanı yöntemi kullanılmamıştır. Postoperatif renal hasarlanmanın genel olarak komplikasyonlar, morbidite ve mortaliteyi arttırdığı vurgulanmaktadır. Çalışmamızda diyaliz gerektiren kalıcı renal morbidite $\% 72.4$ hastada, tüm nedenli 28 günlük mortalite \%47.6 iken, 3 aylık mortalite ise \%71 hastada izlenmiştir. Renal hasarlanmanın morbidite ve mortalite üzerine bu yüksek oranlı olumsuz etkileri birçok çalışmada benzer oranlarda gözlenmektedir. Renal nedenli mortalite için \%50-80 aralığında verilmiştir, ancak bunlar yalnızca renal nedenli mortalitedir, bizim sonucumuz ise renal yetmezlik gelişen hastalarda tüm nedenli mortaliteyi içermektedir ${ }^{(14,21-25)}$.

Renal hasar; kardiyak cerrahinin kısa ve uzun süreli, morbidite ve mortalite ileilişkili önemli ve yaygın komplikasyonlarından biridir. Erken tanıma, nefro- 
toksisiteden kaçınma, sıvı dengesinde optimizasyonun sağlanması renal hasarın neden olduğu morbidite ve mortaliteyi azaltır ${ }^{[26]}$.

Sonuç olarak, araştırmamızda postoperatif dializ gerektiren böbrek yetmezliği için riskli olabilecek perioperatif durumlar; diyabet, önceden geçirilmiş miyokard enfarktüsü, kötü sol ventrikül $\mathrm{EF}(<\% 50)$, preoperatif ve KPB sırasındaki anemi, yakın zamanda kontrast madde maruziyeti, NSAI ve antihipertansif ilaçların kullanımı, uzamış KPB süresi, kompleks cerrahi tipleri, IABP ve ECMO kullanımı olarak gözlenmiştir. Literatürde risk faktörü olarak değerlendirilen birçok etiyolojik faktörün hasta grubumuzda mevcut olduğu açıktır. Bu bilgiler ışı̆̆ında hastalarımızdaki renal hasarlanmanın etiyolojisinde hem preoperatif özelliklerin hem de intraoperatif faktörlerin rol oynamış olduğunu düşünmekteyiz.

Kardiyak cerrahi; tüm organ perfüzyonlarının etkilendiği karmaşık patofizyolojik durumları içermektedir. Peroperatif hastalarda birçok komplikasyon gelişmektedir. Bunlardan en önemlisi böbreğin çeşitli derecelerdeki yetmezlikleri olup, ameliyat sonrası sağ kalımı etkileyerek, 28 günlük ve 3 aylık mortaliteyi arttırmaktadır. Araştırdığımız hasta grubunda da oldukça yüksek mortalite oranları gözlenmiş, bu da böbrek fonksiyonlarının önemini bir kez daha vurgulamıştır.

\section{KAYNAKLAR}

1. Yeo KK, Li Z, Yeun JY, Amsterdam E. Severity of chronic kidney disease as a risk factor for operative mortality in nonemergent patients in the california coronary artery bypass graft surgery outcomes reporting program. Am J Cardiol. 2008;101:1269-74.

https://doi.org/10.1016/j.amjcard.2008.01.002

2. Chikwe J, Castillo JG, Rahmanian PB, Akujufo A, Adams $\mathrm{DH}$, Filsoufi $\mathrm{F}$. The impact of moderate-to-end-stage renal failure on outcomes after coronary artery bypass graft surgery. J Cardiothorac Vasc Anesth. 2010;24: 574-9. https://doi.org/10.1053/j.jvca.2009.10.017

3. Loef BG, Epema AH, Smilde TD, Henning RH, Ebels $T$, Navis G, Stegeman CA. Immediate postoperative renal function deterioration in cardiac surgical patients pre- dicts in-hospital mortality and long-term survival. J Am Soc Nephrol. 2005;16:195-200. https://doi.org/10.1681/ASN.2003100875

4. Brown JR, Cochran RP, Leavitt BJ, Dacey LJ, Ross CS, Mackenzie TA, et al. Multivariable prediction of renal insufficiency developing after cardiac surgery. Northern New England Cardiovascular Disease Study Group. Circulation. 2007;116:139-43. https://doi.org/10.1161/CIRCULATIONAHA.106.677070

5. Chertow GM, Lazarus JM, Christiansen CL, Cook EF, Hammermeister KE, Grover F, Daley J. Preoperative renal risk stratification. Circulation. 1997 Feb 18; 95(4):878-84. https://doi.org/10.1161/01.CIR.95.4.878

6. Filsoufi F, Rahmanian PB, Castillo JG, Silvay G, Carpentier A, Adams DH. Predictors and early and late outcomes of dialysis-dependent patients in contemporary cardiac surgery. J Cardiothorac Vasc Anesth. 2008;22: 522-9. https://doi.org/10.1053/j.jvca.2008.01.015

7. Huen S, Parikh CR. Predicting acute kidney injury following cardiac surgery: a systematic review. The Annals of Thoracic Surgery. 2012;93:337-47. https://doi.org/10.1016/j.athoracsur.2011.09.010

8. Bove T, Monaco F, Covello RD, Zangrillo A. Acute renal failure and cardiac surgery. HSR Proc Intensive Care Cardiovasc Anesth. 2009;1:13-21.

9. Navarro, Lais $\mathrm{H}, \mathrm{Chew}$, Michelle $\mathrm{S}$. Postoperative acute kidney injury: a never-ending challenge. European Journal of Anaesthesiology. 2018;35:639-40. https://doi.org/10.1097/EJA.0000000000000862

10. Mao H, Katz N, Ariyanon W, Blanca-Martos L, et al. Cardiac surgery-associated acute kidney injury. Cardiorenal Medicine. 2013;3:178-99. https://doi.org/10.1159/000353134

11. Conlon PJ, Stafford-Smith M, White WD, Newman MF, King S, Winn MP, Landolfo K. Acute renal failure following cardiac surgery. Nephrol Dial Transplant. 1999;14:1158-62. https://doi.org/10.1093/ndt/14.5.1158

12. Ivert T, Holzmann MJ, Sartipy U. Survival in patients with acute kidney injury requiring dialysis after coronary artery bypass grafting. Eur J Cardiothorac Surg. 2014;45:312-7. https://doi.org/10.1093/ejcts/ezt247

13. Tang IY, Murray PT. Prevention of perioperative acute renal failure: what works? Best Practice \& Research Clinical Anaesthesiology. 2004;18:91-111. https://doi.org/10.1016/j.bpa.2003.09.006

14. Thakar CV, Arrigain S, Worley S, et al. A clinical Score to predict acute renal failure after Cardiac surgery. J Am Soc Nephrol. 2005;16:162-8. https://doi.org/10.1681/ASN.2004040331 
15. Miceli A,Romeo F, Glauber M, De Siena PM, Caputo M, Angelini GD. Preoperative anemia increases mortality and postoperative morbidity after cardiac surgery. Journal of Cardiothoracic Surgery 2014;9:137. https://doi.org/10.1186/1749-8090-9-137

16. Ezekowitz JA, McAlister FA, Armstrong PW. Anemia is common in heart failure and is associated with poor outcomes: insights from a cohort of 12065 patients with new-onset heart failure. Circulation. 2003; 107:223-5.

https://doi.org/10.1161/01.CIR.0000052622.51963.FC

17. Mao H, Katz N, Ariyanon W, Blanca-Martos L, Adýbelli Z, Giuliani A, et al. Cardiac surgery-associated acute kidney injury. Cardiorenal Med. 2013;3:178-99. https://doi.org/10.1159/000353134

18. Kumar AB, Suneja M, Bayman EO, Weide GD, Tarasi M. Association between postoperative acute kidney injury and duration of cardiopulmonary bypass: a metaanalysis. J Cardiothorac Vasc Anesth. 2012;26:64-9. https://doi.org/10.1053/j.jvca.2011.07.007

19. Karkouti K, Grocott HP, Hall R, Jessen ME, Kruger C, Lerner $A B$, et al. Interrelationship of preoperative anemia, intraoperative anemia, and red blood cell transfusion as potentially modifiable risk factors for acute kidney injury in cardiac surgery: a historical multicentre cohort study. Can J Anaesth. 2015;62:377-84. https://doi.org/10.1007/s12630-014-0302-y

20. Loor G, Rajeswaran J, Li L, Sabik JF, Blackstone EH, McCrae KR, Koch CG. The least of 3 evils: exposure to red blood cell transfusion, anemia, or both? J Thorac Cardiovasc Surg. 2013;146:1480-7.

https://doi.org/10.1016/j.jtcvs.2013.06.033

21. O'Neal JB, Shaw AD, Frederic T, Billings IV. Acute kidney injury following cardiac surgery: current understanding and future directions. Crit Care. 2016;20:187. https://doi.org/10.1186/s13054-016-1352-z

22. Thakar CV, Worley S, Arrigain S, Yared JP, Paganini EP. Influence of renal dysfunction on mortality after cardiac surgery: modifying effect of preoperative renal function. Kidney Int. 2005;67:1112-9. https://doi.org/10.1111/j.1523-1755.2005.00177.x

23. Haase M, Haase-Fielitz A, Bagshaw SM, Ronco C, Bellomo R. Cardiopulmonary bypass-associated acute kidney injury: a pigment nephropathy? Contrib Nephrol. 2007;156:340-53. https://doi.org/10.1159/000102125

24. Cosentino F, Chaff C, Piedmonte M. Risk factors influencing survival in ICU acute renal failure. Nephrol Dial Transplant. 1994;9:179-82.

25. Liaño F, Junco E, Pascual J, Madero R, Verde E. The spectrum of acute renal failure in the intensive care unit compared with that seen in other settings. The madrid acute renal failure study group. Kidney Int. 1998;53:16-24.

26. Wang Y, Bellomo R. Cardiac surgery-associated acute kidney injury: risk factors, pathophysiology and treatment. Nature Reviews Nephrology. 2017;13:697-711. https://doi.org/10.1038/nrneph.2017.119 